Article

\title{
Aberrant Lipid Metabolism in Hepatocellular Carcinoma Revealed by Liver Lipidomics
}

\author{
Zhao Li ${ }^{1}$, Ming Guan ${ }^{2,3}$, Yu Lin ${ }^{2}$, Xiao Cui ${ }^{1}$, Yangyang Zhang ${ }^{2}$, Zhenwen Zhao ${ }^{2,3, *}$ \\ and Jiye $\mathrm{Zhu}^{1}$ \\ 1 Department of Hepatobiliary Surgery, Peking University People's Hospital, Beijing 100044, China; \\ lizhao@bjmu.edu.cn (Z.L.); cx_2077@bjmu.edu.cn (X.C.); gandanwk@vip.sina.com (J.Z.) \\ 2 Beijing National Laboratory for Molecular Sciences, Key Laboratory of Analytical Chemistry for Living \\ Biosystems, Institute of Chemistry Chinese Academy of Sciences, Beijing Mass Spectrum Center, \\ Beijing 100190, China; guanming@iccas.ac.cn (M.G.); linyu@iccas.ac.cn (Y.L.); zhangyy@iccas.ac.cn (Y.Z.) \\ 3 Graduate School, University of Chinese Academy of Sciences, Beijing 100049, China \\ * Correspondence: zhenwenzhao@iccas.ac.cn; Tel.: +86-10-6256-1239
}

Received: 25 October 2017; Accepted: 23 November 2017; Published: 28 November 2017

\begin{abstract}
Background: The aim of this study was to characterize the disorder of lipid metabolism in hepatocellular carcinoma (HCC). HCC is a worldwide disease. The research into the disorder of lipid metabolism in HCC is very limited. Study of lipid metabolism in liver cancer tissue may have the potential to provide new insight into HCC mechanisms. Methods: A lipidomics study of HCC based on Ultra high performance liquid chromatography-electronic spray ionization-QTOF mass spectrometer (UPLC-ESI-QTOF MS) and Matrix assisted laser desorption ionization-fourier transform ion cyclotron resonance mass spectrometer (MALDI-FTICR MS) was performed. Results: Triacylglycerols (TAGs) with the number of double bond (DB) $>2$ (except 56:5 and 56:4 TAG) were significantly down-regulated; conversely, others (except 52:2 TAG) were greatly up-regulated in HCC tissues. Moreover, the more serious the disease was, the higher the saturated TAG concentration and the lower the polyunsaturated TAG concentration were in HCC tissues. The phosphatidylcholine (PC), phosphatidylethanolamine (PE) and phosphatidylinositol (PI) were altered in a certain way. Sphingomyelin (SM) was up-regulated and ceramide (Cer) were down-regulated in HCC tissues. Conclusions: To our knowledge, this is the first such report showing a unique trend of TAG, PC, PE and PI. The use of polyunsaturated fatty acids, like eicosapentanoic and docosahexanoic acid, as supplementation, proposed for the treatment of Non-alcoholic steatohepatitis (NASH), may also be effective for the treatment of HCC.
\end{abstract}

Keywords: triacylglycerols; phosphatidylcholine; ceramide; mass spectrometry; UPLC-ESI-QTOF MS

\section{Introduction}

Liver cancer is one of ten leading cancer types of cancer death, and estimated new liver cancer cases and deaths were 33,190 and 23,000 respectively in the United States in 2014 [1]. Hepatocellular carcinoma (HCC) accounts for approximately $75 \%$ of all primary liver cancers, and chronic infection with either hepatitis $\mathrm{C}$ virus (HCV) or hepatitis B virus (HBV) leading to cirrhosis is the most common cause of HCC [2]. Although there are multiple therapeutic ways to treat HCC, such as liver resection, transplantation and ablation, the prognosis of HCC is still unsatisfying [3] and five-year survival rates are $17 \%$ in the United States (http://seer.cancer.gov/statfacts/html/livibd.html). A considerable number of gene expression studies have been undertaken targeted at understanding the progression of HCC [2]; however, the molecular-based mechanism that contributes to the pathogenesis of HCC is still poorly understood. 
Lipid metabolism is one of the essential liver functions and the aberrant metabolism of liver has been reported to cause liver diseases such as inflammation and fibrosis [4]. Human liver pathogenesis of non-alcoholic fatty liver disease (NAFLD) is characterized by numerous changes in hepatic lipid composition and free fatty acid ratios [5,6]. High fat content and fructose consumption are the risk factors that may lead to NAFLD [7,8]. Significant expression changes of several phosphatidylcholines (PCs) and related enzymes were identified in the mouse livers of HBV infection and HBV-mediated regeneration defects [9]. Non-alcoholic steatohepatitis (NASH) represents a risk factor for the development of HCC, and analyses of liver samples from patients with NASH or NASH-related HCC show an elevated expression of the elongase ELOVL6 [10], which catalyzes the elongation of C16 to C18 fatty acids, and has been shown to promote NASH [11,12]. Patterson and co-workers investigated the disorder of metabolites and lipids in plasma of HCC patients. They found that HCC was associated with increased plasma levels of glycodeoxycholate, deoxycholate 3-sulfate, bilirubin, biliverdin, the fetal bile acids ( $7 \alpha$-hydroxy-3-oxochol-4-en-24-oic acid and 3-oxochol-4,6-dien-24-oic acid), and reduced levels of lysophosphocholines (LPCs), lignoceric acid and nervonic acid [13]. Although the reason for these lipid molecules being either elevated or attenuated in plasma is not clear yet, lipidomics analyses may provide new biomarkers for HCC. Recently, a lipidomic analysis in a series of HCC cells was performed, and revealed that decreased palmitic acyl (C16:0)-containing glycerophospholipids were positively associated with metastatic abilities of HCC cells [14]. However, the research into the disorder of lipid metabolism in HCC tissues is very limited. The elucidations of the disorder of lipid metabolism in HCC tissues can significantly expanded our knowledge and engender new insights into HCC pathobiology [15].

Comprehensive study on the lipid changes in tissue at the molecular level is helpful to discover the role of lipid metabolism during tumor development and its mechanism, determine the key lipid metabolic pathways and related enzymes, and provide important basis for effective diagnosis and treatment. Therefore, in this study, we conducted lipidomic analyses in HCC and para-carcinoma tissues, to investigate the underlying molecular mechanism of HCC progression, using ultra performance liquid chromatography-electrospray ionization-quadrupole time-of-flight mass spectrometry (UPLC-ESI-QTOF MS) and matrix-assisted laser desorption ionization Fourier transform ion cyclotron resonance mass spectrometry (MALDI-FTICR MS).

\section{Results}

\subsection{Profile Analysis of Lipids in Hepatocellular Carcinoma (HCC) and Para-Carcinoma Tissues by UPLC-ESI-QTOF MS}

Using the UPLC-ESI-QTOF MS described above, we performed profile analysis of lipids in liver tissues in both positive and negative ion detection modes. The representative total ion chromatograms (TICs) of lipid extracts from HCC (Figure 1A,C) and corresponding para-carcinoma (Figure 1B,D) tissue obtained by UPLC-ESI (+)-QTOF MS (Figure 1A,B) and UPLC-ESI (-)-QTOF MS (Figure 1C,D) are shown in Figure 1. With the aid of the powerful analytical technique, many lipids were separated and identified. It was found that TAGs, glycerophospholipids and sphingolipids were the major components of liver lipids. The glycerophospholipids and sphingolipids were eluted between three and seven minutes and TAGs were eluted between seven to ten minutes.

\subsection{Orthogonal Partial Least Squared Discriminant Analysis (OPLS-DA) for Discrimination of HCC (HCC Group) and Para-Carcinoma Tissues (Para-Carcinoma Group)}

All observations acquired by the UPLC-ESI-QTOF MS-based lipidomics approach were integrated and co-analyzed using supervised OPLS-DA to differentiate HCC (HCC group) and para-carcinoma tissues (para-carcinaoma group). As presented in Figure 2A,C, a separation was observed between HCC group and para-carcinoma group, and similar results are also shown in Figure S1A,C illustrating the difference between the high TNM (tumor node metastasis) grade (III, IV) cancer tissues (C-H TNM) 
and low TNM grade (I, II) cancer tissues (C-L TNM), which suggested that lipid metabolic perturbations were evident and dependent on the pathological condition in the samples.
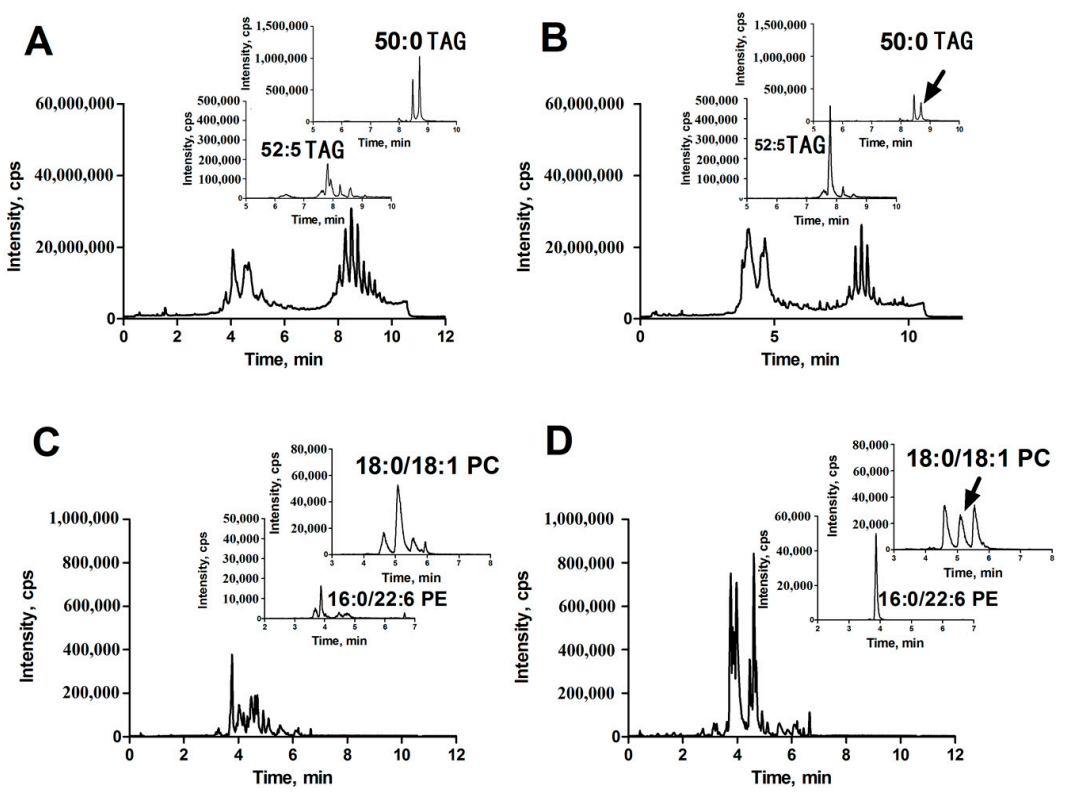

Figure 1. Representative total ion chromatograms (TICs) of lipid extracts obtained by UPLC-ESI (+)-QTOF MS (A,B) and UPLC-ESI (-)-QTOF MS (C,D). (A,C): The lipids were extract from HCC tissue; and (B,D): The lipids were extract from corresponding para-carcinoma tissue. The insets were extracted ion chromatograms (XICs) of indicated ions.
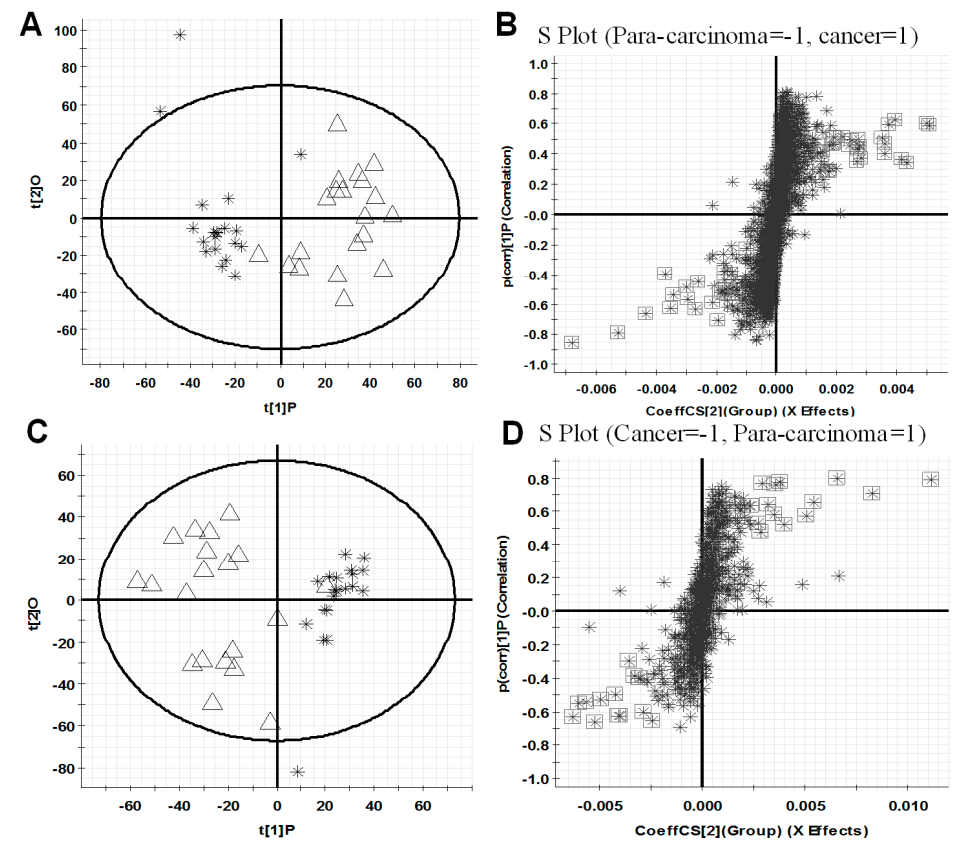

Figure 2. OPLS-DA score plots $(\mathbf{A}, \mathbf{C})$ for discrimination between $\operatorname{HCC}(\Delta, \mathrm{C})$ group and para-carcinoma $(*, \mathrm{P})$ group and S-plots (B,D) for selecting the potential markers based on the data from UPLC-ESI (+)-QTOF MS (A,B) or UPLC-ESI (-)-QTOF MS (C,D). The variables with VIP value $>4.0$ were highlighted with black boxes $(\mathbf{B}, \mathbf{D})$. In $(\mathbf{A}, \mathbf{C}), X$-axis stands for the between group variation, and $Y$-axis stands for the within group variation. In (B,D), $X$-axis stands for the magnitude of viable change, and $Y$-axis stands for the confidence of viable change. 
The variable importance in projection values (VIP) analysis in Markerlynx XS was further carried out to select variables as primary aberrant lipids for distinguishing the two groups. Based on the data, the corresponding S-plot, Figure 2B,D, are shown, respectively. In S-plot, each point represents a variable with specific retention time and mass-to-charge ratio $(\mathrm{m} / \mathrm{z})$ value. In our work, the variables with VIP value $>4.0$ were highlighted with black boxes in Figure 2B,D. In summary, a total of 46 and 24 variables, listed in Table 1, were selected for distinguishing HCC group and para-carcinoma group, respectively, in positive ion and negative ion detection modes. These variables are primary aberrant lipids, greatly distinguish HCC group from para-carcinoma group, and therefore, merit further studies to identify their structures, which might provide new insights into the molecular mechanism of HCC progression. Similar results are also shown in Figure S1B,D, when differentiating the C-H TNM and C-L TNM.

Table 1. The mainly changed lipids in HCC (C) compared with para-carcinoma tissue (P). RT, retention time; TAG, Triacylglycerol; FC, fold change; PG, Phosphatidylglycerol; Dark grey: FC > 1; Light grey: $\mathrm{FC}<1$.

\begin{tabular}{|c|c|c|c|c|c|c|c|}
\hline \multirow{2}{*}{ Aberrant Lipid } & \multirow{2}{*}{ RT (min) } & \multirow{2}{*}{ Quasimolecular Ion } & \multicolumn{2}{|c|}{$m / z$} & \multirow{2}{*}{ Error (ppm) } & \multirow{2}{*}{$p$ Value } & \multirow{2}{*}{$\frac{F C}{(C / P)}$} \\
\hline & & & Detected & Theoretical & & & \\
\hline 46:1 TAG & 7.94 & {$\left[\mathrm{M}+\mathrm{NH}_{4}\right]^{+}$} & 794.7217 & 794.7232 & -1.91 & 0.2163 & 1.60 \\
\hline 46:0 TAG & 8.19 & {$\left[\mathrm{M}+\mathrm{NH}_{4}\right]^{+}$} & 796.7369 & 796.7389 & -2.47 & 0.0890 & 1.79 \\
\hline 48:2 TAG & 7.98 & {$\left[\mathrm{M}+\mathrm{NH}_{4}\right]^{+}$} & 820.7380 & 820.7389 & -1.10 & 0.1409 & 1.62 \\
\hline 48:1 TAG & 8.21 & {$\left[\mathrm{M}+\mathrm{NH}_{4}\right]^{+}$} & 822.7521 & 822.7545 & -2.93 & 0.0365 & 1.58 \\
\hline 48:0 TAG & 8.45 & {$\left[\mathrm{M}+\mathrm{NH}_{4}\right]^{+}$} & 824.7680 & 824.7702 & -2.62 & 0.0065 & 2.23 \\
\hline 50:1 TAG & 8.47 & {$\left[\mathrm{M}+\mathrm{NH}_{4}\right]^{+}$} & 850.7843 & 850.7858 & -1.78 & 0.0092 & 1.29 \\
\hline 50:0 TAG & 8.72 & {$\left[\mathrm{M}+\mathrm{NH}_{4}\right]^{+}$} & 852.7995 & 852.8015 & -2.30 & 0.0006 & 3.60 \\
\hline 51:1 TAG & 8.60 & {$\left[\mathrm{M}+\mathrm{NH}_{4}\right]^{+}$} & 864.7989 & 864.8015 & -3.01 & 0.0143 & 1.82 \\
\hline 52:5 TAG & 7.80 & {$\left[\mathrm{M}+\mathrm{NH}_{4}\right]^{+}$} & 870.7511 & 870.7545 & -3.92 & 0.0006 & 0.38 \\
\hline 52:4 TAG & 8.03 & {$\left[\mathrm{M}+\mathrm{NH}_{4}\right]^{+}$} & 872.7698 & 872.7702 & -0.42 & 0.0000 & 0.53 \\
\hline 52:3 TAG & 8.26 & {$\left[\mathrm{M}+\mathrm{NH}_{4}\right]^{+}$} & 874.7859 & 874.7858 & 0.10 & 0.0339 & 0.79 \\
\hline 52:2 TAG & 8.49 & {$\left[\mathrm{M}+\mathrm{NH}_{4}\right]^{+}$} & 876.8004 & 876.8015 & -1.21 & 0.0193 & 0.87 \\
\hline 52:1 TAG & 8.73 & {$\left[\mathrm{M}+\mathrm{NH}_{4}\right]^{+}$} & 878.8148 & 878.8171 & -2.63 & 0.0001 & 1.82 \\
\hline 52:0 TAG & 8.95 & {$\left[\mathrm{M}+\mathrm{NH}_{4}\right]^{+}$} & 880.8298 & 880.8328 & -3.36 & 0.0027 & 4.32 \\
\hline 53:1 TAG & 8.83 & {$\left[\mathrm{M}+\mathrm{NH}_{4}\right]^{+}$} & 892.8300 & 892.8328 & -3.14 & 0.0007 & 4.46 \\
\hline 54:7 TAG & 7.58 & {$\left[\mathrm{M}+\mathrm{NH}_{4}\right]^{+}$} & 894.7510 & 894.7545 & -3.93 & 0.0004 & 0.27 \\
\hline 54:6 TAG & 7.83 & {$\left[\mathrm{M}+\mathrm{NH}_{4}\right]^{+}$} & 896.7674 & 896.7702 & -3.12 & 0.0081 & 0.51 \\
\hline 54:5 TAG & 8.06 & {$\left[\mathrm{M}+\mathrm{NH}_{4}\right]^{+}$} & 898.7831 & 898.7858 & -3.02 & 0.0000 & 0.53 \\
\hline 54:4 TAG & 8.29 & {$\left[\mathrm{M}+\mathrm{NH}_{4}\right]^{+}$} & 900.7993 & 900.8015 & -2.40 & 0.0006 & 0.68 \\
\hline 54:2 TAG & 8.73 & {$\left[\mathrm{M}+\mathrm{NH}_{4}\right]^{+}$} & 904.8303 & 904.8328 & -2.72 & 0.0090 & 1.51 \\
\hline 54:1 TAG & 8.96 & {$\left[\mathrm{M}+\mathrm{NH}_{4}\right]^{+}$} & 906.8451 & 906.8484 & -3.65 & 0.0006 & 3.17 \\
\hline 56:5 TAG & 8.39 & {$\left[\mathrm{M}+\mathrm{NH}_{4}\right]^{+}$} & 926.8146 & 926.8171 & -2.70 & 0.0413 & 2.30 \\
\hline $56: 4$ TAG & 8.57 & {$\left[\mathrm{M}+\mathrm{NH}_{4}\right]^{+}$} & 928.8298 & 928.8328 & -3.23 & 0.0196 & 1.93 \\
\hline $56: 2$ TAG & 8.95 & {$\left[\mathrm{M}+\mathrm{NH}_{4}\right]^{+}$} & 932.8607 & 932.8641 & -3.64 & 0.0042 & 3.19 \\
\hline 36:4 DAG & 4.99 & {$\left[\mathrm{M}+\mathrm{NH}_{4}\right]^{+}$} & 634.5394 & 634.5405 & -1.73 & 0.0000 & 0.24 \\
\hline 36:3 DAG & 5.42 & {$\left[\mathrm{M}+\mathrm{NH}_{4}\right]^{+}$} & 636.5544 & 636.5561 & -2.75 & 0.0001 & 0.29 \\
\hline 24:1 SM & 5.60 & {$[\mathrm{M}+\mathrm{H}]^{+}$} & 813.6817 & 813.6844 & -3.32 & 0.0141 & 1.73 \\
\hline C24:1 1-deoxy Cer & 6.72 & {$[\mathrm{M}+\mathrm{H}]^{+}$} & 632.6325 & 632.6340 & -2.37 & 0.0003 & 0.48 \\
\hline 22:0 Cer & 6.20 & {$\left[\mathrm{M}+\mathrm{HCOO}^{-}\right.$} & 666.6029 & 666.6042 & -1.94 & 0.0005 & 0.65 \\
\hline 23:0 Cer & 6.44 & {$\left[\mathrm{M}+\mathrm{HCOO}^{-}\right.$} & 680.6181 & 680.6198 & -2.57 & 0.0000 & 0.55 \\
\hline 24:0 Cer & 6.65 & {$\left[\mathrm{M}+\mathrm{HCOO}^{-}\right.$} & 694.6343 & 694.6355 & -1.72 & 0.0012 & 0.65 \\
\hline \multirow{2}{*}{ 16:0/16:1 PC } & 3.97 & {$[\mathrm{M}+\mathrm{H}]^{+}$} & 732.5524 & 732.5538 & -1.89 & 0.0008 & 2.76 \\
\hline & 3.89 & {$\left[\mathrm{M}+\mathrm{HCOO}^{-}\right.$} & 776.5434 & 776.5447 & -1.68 & 0.0040 & 3.17 \\
\hline \multirow{2}{*}{ 16:0/16:0 PC } & 4.46 & {$[\mathrm{M}+\mathrm{H}]^{+}$} & 734.5680 & 734.5694 & -1.95 & 0.0315 & 1.43 \\
\hline & 4.40 & {$[\mathrm{M}+\mathrm{HCOO}]^{-}$} & 778.5589 & 778.5604 & -1.87 & 0.0047 & 1.55 \\
\hline 16:0/18:2 PC & 4.00 & {$\left[\mathrm{M}+\mathrm{HCOO}^{-}\right.$} & 802.5597 & 802.5604 & -0.82 & 0.0015 & 0.68 \\
\hline 16:0/18:1 PC & 4.45 & {$\left[\mathrm{M}+\mathrm{HCOO}^{-}\right.$} & 804.5749 & 804.5760 & -1.37 & 0.0002 & 1.41 \\
\hline 16:0/20:4 PC & 3.98 & {$[\mathrm{M}+\mathrm{H}]^{+}$} & 782.5687 & 782.5694 & -0.93 & 0.0854 & 0.78 \\
\hline $16: 0 / 20: 3 \mathrm{PC}$ & 4.23 & {$[\mathrm{M}+\mathrm{H}]^{+}$} & 784.5836 & 784.5851 & -1.89 & 0.1719 & 1.31 \\
\hline \multirow{2}{*}{$16: 0 / 22: 6$ PC } & 3.85 & {$[\mathrm{M}+\mathrm{H}]^{+}$} & 806.5679 & 806.5694 & -1.86 & 0.0228 & 0.58 \\
\hline & 3.80 & {$\left[\mathrm{M}+\mathrm{HCOO}^{-}\right.$} & 850.5585 & 850.5604 & -2.18 & 0.0003 & 0.54 \\
\hline $18: 2 / 18: 2$ PC & 3.73 & {$[\mathrm{M}+\mathrm{H}]^{+}$} & 782.5675 & 782.5694 & -2.47 & 0.0007 & 0.32 \\
\hline \multirow{2}{*}{ 18:0/18:1 PC } & 5.16 & {$[\mathrm{M}+\mathrm{H}]^{+}$} & 788.6138 & 788.6164 & -3.27 & 0.0009 & 2.68 \\
\hline & 5.08 & {$\left[\mathrm{M}+\mathrm{HCOO}^{-}\right.$} & 832.6057 & 832.6073 & -1.93 & 0.0001 & 2.63 \\
\hline 18:0/20:4 PC & 4.59 & {$[\mathrm{M}+\mathrm{H}]^{+}$} & 810.5988 & 810.6007 & -2.38 & 0.3424 & 0.84 \\
\hline \multirow{2}{*}{ 18:0/20:3 PC } & 4.87 & {$[\mathrm{M}+\mathrm{H}]^{+}$} & 812.6139 & 812.6164 & -3.05 & 0.0105 & 1.83 \\
\hline & 4.81 & {$\left[\mathrm{M}+\mathrm{HCOO}^{-}\right.$} & 856.6053 & 856.6073 & -2.34 & 0.0038 & 1.68 \\
\hline
\end{tabular}


Table 1. Cont.

\begin{tabular}{|c|c|c|c|c|c|c|c|}
\hline \multirow{2}{*}{ Aberrant Lipid } & \multirow{2}{*}{ RT (min) } & \multirow{2}{*}{ Quasimolecular Ion } & \multicolumn{2}{|c|}{$m / z$} & \multirow{2}{*}{ Error (ppm) } & \multirow{2}{*}{$p$ Value } & \multirow{2}{*}{$\begin{array}{c}\mathrm{FC} \\
(\mathrm{C} / \mathrm{P})\end{array}$} \\
\hline & & & Detected & Theoretical & & & \\
\hline 18:0/22:6 PC & 4.44 & {$[\mathrm{M}+\mathrm{H}]^{+}$} & 834.5988 & 834.6007 & -2.31 & 0.0407 & 0.63 \\
\hline 16:0/18:1 PE & 3.89 & {$[\mathrm{M}-\mathrm{H}]^{-}$} & 716.5218 & 716.5236 & -2.48 & 0.0039 & 3.33 \\
\hline \multirow[b]{2}{*}{ 16:0/22:6 PE } & 3.92 & {$[\mathrm{M}+\mathrm{H}]^{+}$} & 764.5199 & 764.5225 & -3.38 & 0.0006 & 0.45 \\
\hline & 3.87 & {$[\mathrm{M}-\mathrm{H}]^{-}$} & 762.5056 & 762.5079 & -3.05 & 0.0000 & 0.51 \\
\hline \multirow{2}{*}{ 16:0/22:5 PE } & 4.21 & {$[\mathrm{M}+\mathrm{H}]^{+}$} & 766.5391 & 766.5381 & 1.26 & 0.0236 & 2.37 \\
\hline & 4.17 & {$[\mathrm{M}-\mathrm{H}]^{-}$} & 764.5224 & 764.5236 & -1.54 & 0.0133 & 1.68 \\
\hline 16:0/20:4 PE & 4.03 & {$[\mathrm{M}-\mathrm{H}]^{-}$} & 738.5066 & 738.5079 & -1.76 & 0.2755 & 1.11 \\
\hline \multirow{2}{*}{ 16:1/22:2 PE } & 4.95 & {$[\mathrm{M}+\mathrm{H}]^{+}$} & 770.5683 & 770.5694 & -1.47 & 0.0182 & 2.31 \\
\hline & 4.85 & {$[\mathrm{M}-\mathrm{H}]^{-}$} & 768.5532 & 768.5549 & -2.18 & 0.0092 & 1.61 \\
\hline 18:1/22:5 PE & 4.52 & {$[\mathrm{M}+\mathrm{H}]^{+}$} & 792.5519 & 792.5538 & -2.37 & 0.0131 & 0.58 \\
\hline 18:0/18:2 PE & 4.00 & {$[\mathrm{M}+\mathrm{H}]^{+}$} & 742.5380 & 742.5392 & -1.62 & 0.0000 & 0.65 \\
\hline 18:0/18:1 PE & 4.45 & {$[\mathrm{M}+\mathrm{H}]^{+}$} & 744.5533 & 744.5549 & -2.12 & 0.0002 & 1.41 \\
\hline 18:0/20:3 PE & 5.01 & {$[\mathrm{M}+\mathrm{H}]^{+}$} & 768.5525 & 768.5549 & -3.10 & 0.0043 & 14.48 \\
\hline 18:0/20:1 PE & 5.08 & {$[\mathrm{M}+\mathrm{H}]^{+}$} & 772.5841 & 772.5862 & -2.69 & 0.0002 & 2.60 \\
\hline 18:1/22:5 PE & 4.46 & {$[\mathrm{M}+\mathrm{H}]^{+}$} & 790.5376 & 790.5392 & -2.06 & 0.0056 & 0.65 \\
\hline $18: 2 / 18: 2$ PG & 2.74 & {$[\mathrm{M}-\mathrm{H}]^{-}$} & 769.5004 & 769.5025 & -2.73 & 0.0000 & 0.31 \\
\hline 18:1/18:2 PG & 3.16 & {$[\mathrm{M}-\mathrm{H}]^{-}$} & 771.5164 & 771.5182 & -2.28 & 0.0000 & 0.37 \\
\hline 18:1/18:1 PG & 3.57 & {$[\mathrm{M}-\mathrm{H}]^{-}$} & 773.5320 & 773.5338 & -2.34 & 0.1034 & 0.51 \\
\hline 16:0/18:2 PI & 3.24 & {$[\mathrm{M}-\mathrm{H}]^{-}$} & 833.5166 & 833.5186 & -2.34 & 0.0056 & 0.64 \\
\hline 16:0/18:1 PI & 3.67 & {$[\mathrm{M}-\mathrm{H}]^{-}$} & 835.5328 & 835.5342 & -1.68 & 0.0205 & 3.75 \\
\hline 18:2/18:2 PI & 3.19 & {$[\mathrm{M}-\mathrm{H}]^{-}$} & 857.5170 & 857.5186 & -1.87 & 0.1499 & 1.23 \\
\hline 18:0/18:2 PI & 3.83 & {$[\mathrm{M}-\mathrm{H}]^{-}$} & 861.5486 & 861.5499 & -1.51 & 0.0000 & 0.48 \\
\hline 18:0/20:3 PI & 4.03 & {$[\mathrm{M}-\mathrm{H}]^{-}$} & 887.5642 & 887.5655 & -1.46 & 0.0256 & 1.52 \\
\hline
\end{tabular}

\subsection{Identification of the Aberrant Lipids in HCC Group}

The structures of these aberrant lipids were identified by database searching and were confirmed by standard lipids and/or MS/MS data. The protocol was similar to our previous work [16]. Here, a few examples were shown as below to further explain the detailed process.

In positive ion detection mode, two variables with retention times (RT) of 8.72 and $7.80 \mathrm{~min}$ and corresponding mass-to-charge ratios $(\mathrm{m} / \mathrm{z})$ of 852.7995 (up-regulated, shown in Figure $1 \mathrm{~A}, \mathrm{~B}$ ) and 870.7511 (down-regulated, shown in Figure 1A,B) were selected as two of primary changed lipids in HCC group. The database (LIPID MAPS) search results for the given $m / z$ at 852.7995 and 870.7511 were ammonium adduct of 50:0 TAG and 52:5 TAG with a mass error $-2.30 \mathrm{ppm}$ and $-3.92 \mathrm{ppm}$, respectively. The MS/MS spectrum with RT at $8.72 \mathrm{~min}$ in positive-ion detection mode (Figure 3A) showed serial of signals with $\mathrm{m} / \mathrm{z}$ at 852.7995, 857.7554, 551.5035 and 579.5346, corresponding to the [50:0 TAG $\left.+\mathrm{NH}_{4}\right]^{+}$(ammonium adduct), [50:0 TAG $\left.+\mathrm{Na}\right]^{+}$(sodium adduct), [50:0 TAG $\left.+\mathrm{NH}_{4}-17-\mathrm{C}_{16} \mathrm{H}_{32} \mathrm{O}_{2}\right]^{+}$and [50:0 TAG $\left.+\mathrm{NH}_{4}-17-\mathrm{C}_{18} \mathrm{H}_{36} \mathrm{O}_{2}\right]+$ (formed by neutral loss of $\mathrm{NH}_{3}$ and fatty acyl chain from ammonium adduct of TAG). This information and combinational restrictions arising from elemental composition allowed deducing the molecular species to be 18:0/16:0/16:0 TAG. Carefully investigating the MS/MS data at $7.80 \mathrm{~min}$ in positive-ion detection mode (Figure 3B), we could infer that the ions with $m / z$ at 870.7511, 875.7059, 547.4695 and 573.4866 were corresponding to $\left[52: 5 \mathrm{TAG}+\mathrm{NH}_{4}\right]^{+}$, [52:5 TAG $\left.+\mathrm{Na}\right]^{+}$, [52:5 TAG $\left.+\mathrm{NH}_{4}-17-\mathrm{C}_{20} \mathrm{H}_{34} \mathrm{O}_{2}\right]^{+}$and [52:5 TAG $\left.+\mathrm{NH}_{4}-17-\mathrm{C}_{18} \mathrm{H}_{32} \mathrm{O}_{2}\right]^{+}$and the molecular species to be 20:3/14:0/18:2 TAG. Therefore, 50:0 TAG and 52:5 TAG were confirmed.

In positive ion detection mode, a variable with RT at $5.16 \mathrm{~min}$ and $\mathrm{m} / \mathrm{z}$ at 788.6138 (up-regulated, shown in Figure 1C,D) was selected as one of the primary changed lipids in HCC group. The database (LIPID MAPS) search results for the given $m / z$ at 784.5838 were 36:1 PC or 39:3 PE with a mass error $-3.27 \mathrm{ppm}$. The MS/MS spectrum with RT at $5.16 \mathrm{~min}$ in positive-ion detection mode (Figure 3C) showed that an ion with $m / z$ at 184.0795 (phosphorylcholine) was the main fragment ion. Based on our previous studies, it can be inferred that this ion $(m / z: 788.6138)$ was likely a protonated PC. In negative ion detect mode, in the MS data with RT at $5.08 \mathrm{~min}$, a quasimolecular ion with $\mathrm{m} / \mathrm{z}$ at 832.6057 was shown. In the mobile phase, an ammonium formate was added as additive to enhance the ionization efficiency. Therefore, the ion with $\mathrm{m} / \mathrm{z}$ at 832.6057 was likely the quasimolecular ion of 
$[\mathrm{M}+\mathrm{HCOO}]^{-}$. The human metabolome database (HMDB) search results for the given $m / z$ at 832.6057 were also showed that this compound was likely 36:1 PC with a mass error $-1.93 \mathrm{ppm}$. The MS/MS data (Figure 3D) with RT at $5.08 \mathrm{~min}$ showed that two ions with $\mathrm{m} / \mathrm{z}$ at $281.2482\left(\mathrm{C}_{17} \mathrm{H}_{34} \mathrm{COO}^{-}\right.$) and at $283.2617\left(\mathrm{C}_{17} \mathrm{H}_{36} \mathrm{COO}^{-}\right)$, corresponding to two fatty acyl chains linked to glycerol backbone in the structure of PC, were the main fragment ions. All together, we inferred that the variable with RT at 5.16 min was 18:0/18:1 PC.

In positive ion detection mode, a variable with RT at $3.92 \mathrm{~min}$ and $\mathrm{m} / \mathrm{z}$ at 764.5199 (down-regulated, shown in Figure 1C,D) was also selected as one of the primary changed lipids in the HCC group. The database (LIPID MAPS) search results for the given $m / z$ at 764.5199 were 35:6 PC or 36:6 PE with a mass error $-3.38 \mathrm{ppm}$. The MS/MS spectrum with RT at $3.92 \mathrm{~min}$ in positive-ion detection mode (Figure 3E) showed that an ion with $\mathrm{m} / \mathrm{z}$ at 623.5075 (neutral loss of phosphorylethanolamine) was the main fragment ion; it can be inferred that this ion $(m / z: 764.5199)$ was likely a protonated phosphatidylethanolamine (PE). In negative ion detection mode, in the MS data with RT at $3.87 \mathrm{~min}$, a quasimolecular ion with $\mathrm{m} / \mathrm{z}$ at 762.5056 was shown. The database (HMDB) search results for the given $\mathrm{m} / \mathrm{z}$ at 762.5056 also showed that this compound was likely deprotonated 36:6 PE with a mass error $-3.05 \mathrm{ppm}$. The MS/MS data (Figure 3F) with RT at $3.87 \mathrm{~min}$ showed that two ions with $\mathrm{m} / \mathrm{z}$ at $255.2329\left(\mathrm{C}_{15} \mathrm{H}_{32} \mathrm{COO}^{-}\right)$and at $327.2329\left(\mathrm{C}_{21} \mathrm{H}_{32} \mathrm{COO}^{-}\right)$, corresponding to two fatty acyl chains linked to a glycerol backbone in the structure of $\mathrm{PE}$, were the main fragment ions. All together, we inferred that the variable with RT at $3.92 \mathrm{~min}$ was 16:0/22:6 PE.
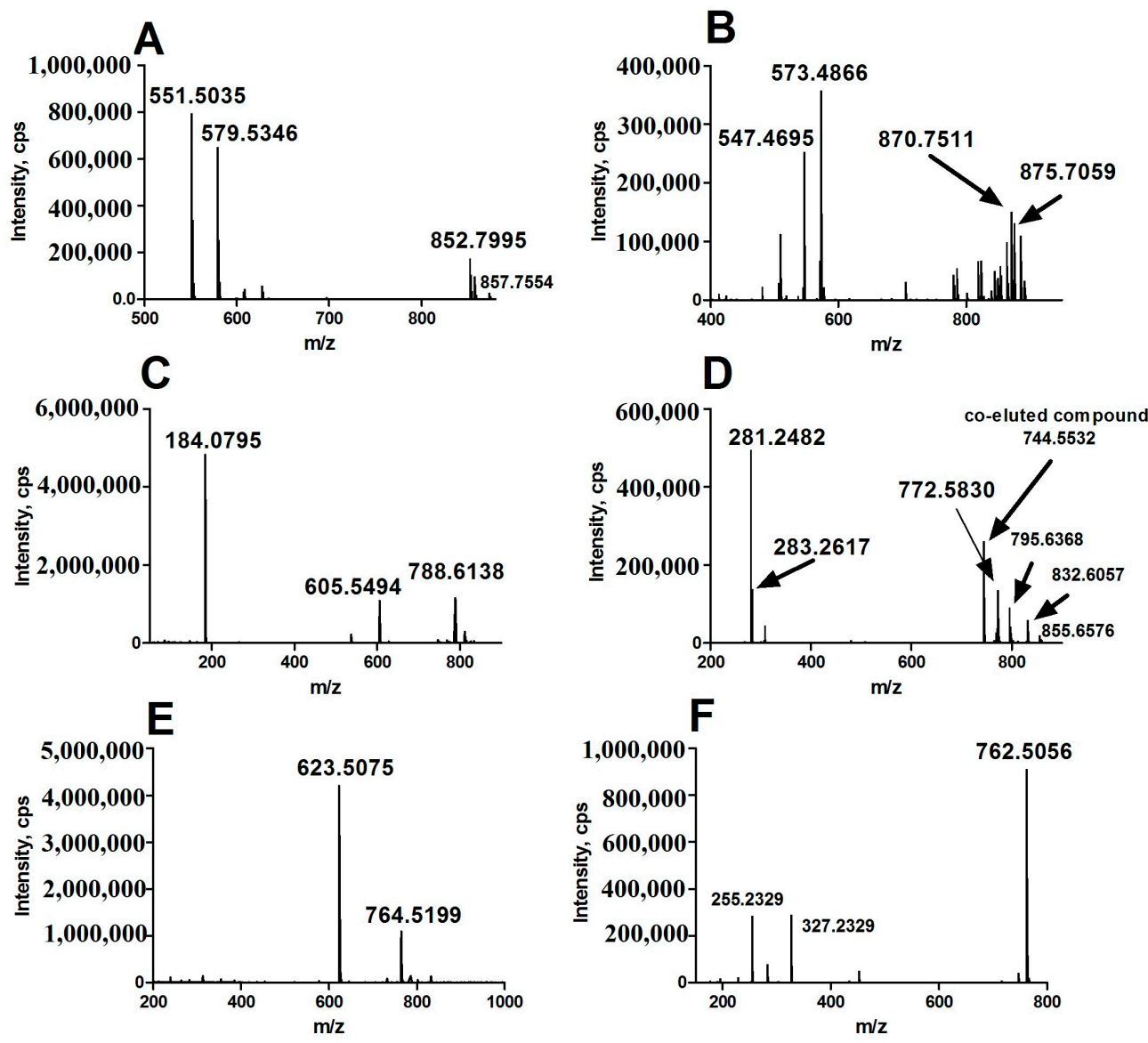

Figure 3. MS/MS data of representative aberrant lipids for structure identification. (A) lipid with RT at 8.72 in positive-ion detection mode; (B) lipid with RT at $7.80 \mathrm{~min}$ in positive-ion detection mode; (C) lipid with RT at 5.16 min in positive-ion detection mode; (D) lipid with RT at $5.16 \mathrm{~min}$ in negative-ion detection mode; (E) lipid with RT at $3.92 \mathrm{~min}$ in positive-ion detection mode; (F) lipid with RT at $3.92 \mathrm{~min}$ in negative-ion detection mode. $\mathrm{m} / \mathrm{z}$ : mass-to-charge ratio. 
Similarly, we identified some other aberrant lipids. In total, 53 lipids were identified as major aberrant lipids in HCC group compared with the para-carcinoma group. More detailed information, including fold change (FC, the ratio of lipid level in HCC group versus para-carcinoma group), $p$ value, etc. is listed in Table 1. Basically, the mainly identified aberrant lipids were TAGs, glycerophospholipids and sphingolipids. The variables simultaneously identified by both positive and negative ion detection modes showed a very consistent trend. For example, the FC of 16:0/22:6 PC were 0.58 and 0.54 in positive and negative ion detection modes, respectively, which further confirmed the reliability and accuracy of our MS-based lipidomics approach.

In addition, as revealed of FC in Table 1, it was found that TAGs with the number of double bonds more than 2 (except 56:5 and 56:4 TAG) were significantly down-regulated; however, TAGs with the number of double bonds equal to or less than 2 (except 52:2 TAG) were greatly up-regulated in HCC tissues. PC, PE and PI, with the number of double bonds equal to 0,1 or 3 , were significantly up-regulated, while PC, PE and PI (except 18:2/18:2 PI), with the number of double bonds equal to 2, 4 or 6, were significantly down-regulated. SM was up-regulated and Cer and PG were down-regulated in HCC tissues. The volcano plot of individual lipid in hepatocellular carcinoma vs. para-carcinoma tissues was plot, shown in Figure 4. 26 specific lipids with FC $<0.5$ or $>2.0$ and $p$ value $<0.05$ were indicated.

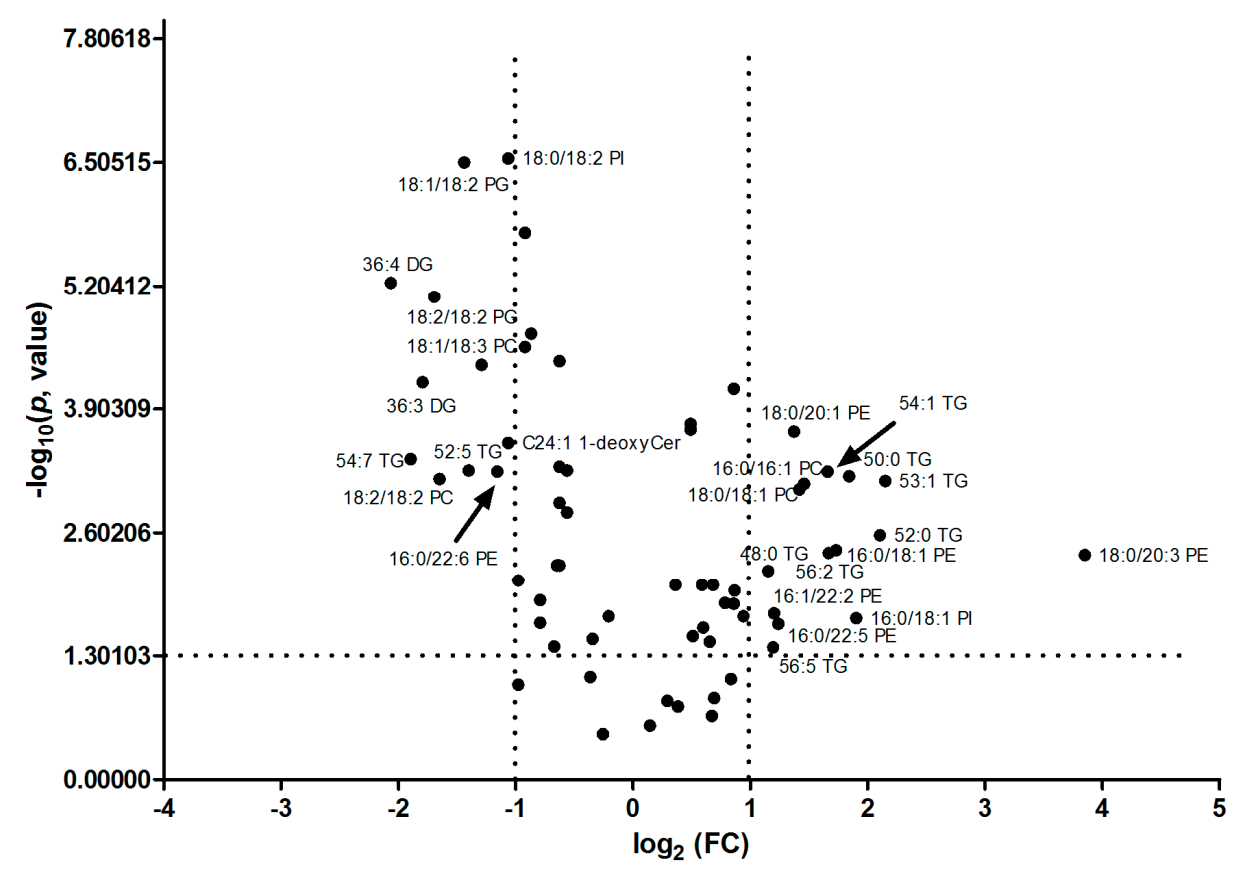

Figure 4. The volcano plot of aberrant lipids in hepatocellular carcinoma (C) vs. para-carcinoma (P) tissues. 26 specific lipids with fold change $(\mathrm{FC})<0.5$ or $>2.0$ and $p$ value $<0.05$ were indicated in the volcano plot. FC: fold-change of $\mathrm{C}$ vs. P.

Further, the major aberrant lipids in the C-H TNM compared with C-L TNM were also identified and listed in Table S1, which showed that TAGs with the number of double bonds more than 4 were down-regulated, and saturated TAGs and TAGs with 1 double bond were up-regulated, although the $p$ value was not significant.

\subsection{Matrix Assisted Laser Desorption Ionization Mass Spectrometry Imaging (MALDI MSI) Analysis of Human Liver Cancer Tissue}

MALDI MSI has been widely applied for the label-free visualization of biological compounds from matrix coated tissue sections [17]. In order to directly visualize the dysfunction of lipids in HCC, silver nanoparticles (AgNPs)-based MALDI MSI was utilized and the results are shown in Figure 5. Hematoxylin-eosin (H\&E) staining was performed to display the histological morphology of HCC and 
para-carcinoma tissues also shown in Figure 5. TAGs and PCs were imaged quite differently between the para-tumor liver tissue and the tumor tissues. The detected TAGs and PCs from MALDI MSI analysis are shown in Table S2. Eight highly unsaturated TAGs (two or more than two double bonds) were found extremely down regulated in the cancer section shown in Table S2. In contrast, 34:1 PC was found highly expressed in the liver cancer tissue section. The MALDI MSI images were quite consistent with the results obtained from UPLC-ESI-QTOF MS.

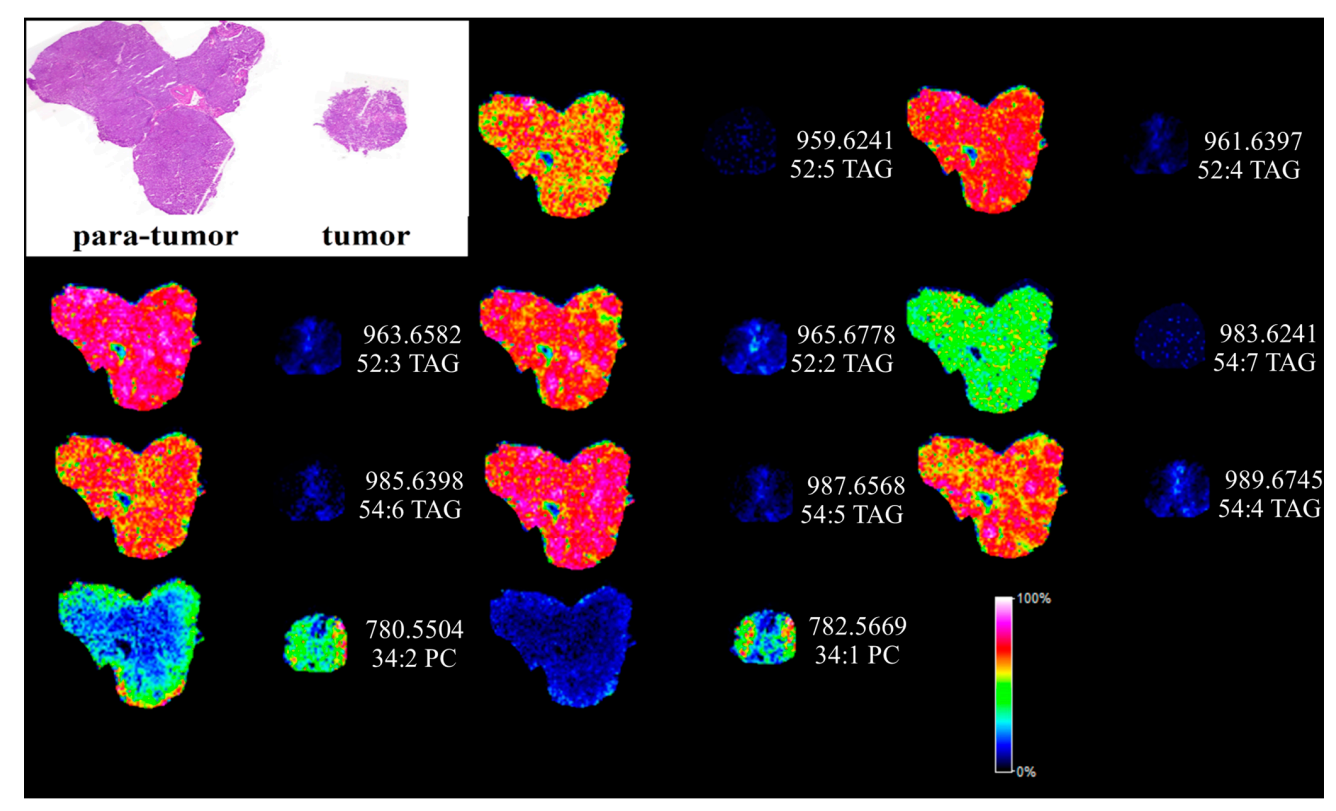

Figure 5. In situ MALDI imaging of lipids in human paracancerous and cancer tissue using AgNPs as matrix and the corresponding H\&E staining image. The liver tissues were sectioned at $10 \mu \mathrm{m}$ and the laser raster step size is $150 \mu \mathrm{m}$.

\section{Discussion}

Hepatocellular carcinoma (HCC) is a highly lethal cancer, with increasing worldwide incidence, that is mainly associated with chronic hepatitis B virus (HBV) and/or hepatitis $\mathrm{C}$ virus (HCV) infections. There are few effective treatments partly because the cell- and molecular-based mechanisms that contribute to the pathogenesis of this tumor type are poorly understood. In this study, 20 HCC tissues (16 HBV-related HCC, one HCV-related HCC, one HBV and HCV-related HCC, and two HCC without $\mathrm{HBV}$ and $\mathrm{HCV}$ infection) and their corresponding para-carcinoma tissues were collected for the study of disease mechanism.

Lipids are one of main components of cells and play essential roles in many cellular processes, such as cell growth, proliferation, differentiation, survival, apoptosis and drug resistance $[18,19]$. Recently, methods developed for lipid analysis, in particularly the method of electrospray ionization mass spectrometry (ESI-MS), realized the rapid and sensitive analysis of the majority of lipids in one analysis. For example, Giavalisco et al. combined an ultra-performance liquid chromatography (UPLC) with a high resolution MS and all-ion MS/MS for the semi-quantitative analysis of lipids extracted from Arabidopsis thaliana leaf, mainly including PC, PE, PG, PI, PS, etc. [20]. MS-based lipidomic analyses have significantly expanded our knowledge related to human physiology and pathology $[15,21,22]$. For example, plasma LPCs levels were decreased in colorectal cancer (CRC) patients, and have been identified as the potential diagnostic biomarker for CRC by ESI-MS [21,22]. Patterson and co-workers also investigated the disorder of metabolites and lipids in plasma of HCC patients [13]. Although the reason for these lipid molecules being either elevated or attenuated in plasma or liver tissue is not clear yet, lipidomic analyses have the potential to provide a new insight for the mechanism of HCC progression. 
In this study, we conducted lipidomic analyses in HCC and para-carcinoma tissues using UPLC-ESI-QTOF MS and MALDI-FTICR MS. Multivariate data analysis was applied for investigating the aberrant lipid metabolism in hepatocellular carcinoma. High-resolution mass spectrometry and its corresponding MS/MS data were combined to accurately identify the structure of these aberrant lipids. Lipid metabolism in HCC was also concerned by Van Thiel DH et al. [23]. Interestingly, in our work, it was found that TAGs with the number of double bonds more than 2 (except 56:5 and 56:4 TAG) were significantly down-regulated; however, TAGs with the number of double bonds equal to or less than 2 (except 52:2 TAG) were greatly up-regulated in HCC tissues. Similar results were also obtained from the MADLI MSI analysis. Moreover, results showed that the more serious the disease was, the higher the saturated TAG concentration and the lower the polyunsaturated TAG concentration were in HCC tissues. PC, PE and PI, with the number of double bonds equal to 0,1 or 3 , were significantly up-regulated, while PC, PE and PI (except 18:2/18:2 PI), with the number of double bonds equal to 2, 4 or 6, significantly down-regulated. The MALDI MSI imaging of 34:1 PC also showed high expression in the tumor section. SM was up-regulated and Cer and PG were down-regulated in HCC tissues. To our knowledge, this is the first such report showing the unique trend of TAG, PC, PE and PI in HCC tissues, although impaired TAG metabolism associated with metabolic syndrome has been observed [24].

In the human body, high levels of plasma TAGs have been linked to cardiovascular disease [25-27]. The level of TAG has already been used as an index for evaluating metabolic syndromes by WHO [28]. There was a trend for increased saturated fatty acids (SFAs) and monounsaturated fatty acids (MUFAs), and a significant decreased polyunsaturated fatty acid (PUFA) associated with diacylglycerol (DAG) and TAG in NAFLD and NASH, compared with controls [5]. In our work, two DAGs and seven TAGs with the number of double bonds more than 2 were significantly decreased, while 14 TAGs with the number of double bonds equal to or less than 2 were greatly increased in HCC tissues compared with para-carcinoma tissues. Similar results were also shown in the images of polyunsaturated TAGs in MALDI MSI. Although the reason for the inhomogeneous change of TAGs was not clear, these changes could play a role in the pathogenesis of HCC.

Glycerophospholipids are major components of the cell membrane, and they have important roles during liver regeneration and lipid metabolism. The plasma lipidomics study revealed significantly increased total plasma monounsaturated fatty acids driven by palmitoleic (16:1 n7) and oleic (18:1 n9) acids content $(p<0.01$ for both acids in both NAFLD and NASH). In addition, linoleic acid (18:2 n6) was decreased $(p<0.05)$, with a concomitant increase in linolenic $(18: 3 \mathrm{n} 6)$ and dihomolinolenic (20:3 n6) acids in both NAFLD and NASH ( $p<0.001$ for most lipid classes) [6]. In our work, coincidentally, PCs containing 16:1 and 18:1 fatty acyl chain were significantly increased, PCs containing 18:2 fatty acyl chain were significantly decreased, and PCs containing 18:3 and 20:3 fatty acyl chain were correspondingly significantly increased in HCC tissues compared with para-carcinoma tissues. In addition, both 16:0/22:6 PC and 18:0/22:6 PC were significantly decreased. The n-3 fatty acid (22:6 fatty acid) has profound anti-inflammatory, antiproliferative, immunomodulatory and metabolic effects [29-32], and the use of eicosapentanoic (20:5 n-3) and docosahexanoic (22:6n-3) acid supplementation for the treatment of NASH has already been proposed [5]. Based on our results, this strategy may also be effective for the treatment of HCC.

Several studies have demonstrated that $70 \%$ of PC synthesized in the liver is mediated through the cytidine 5'-diphosphocholine (CDP)-choline pathway, while the remaining $30 \%$ is produced by the phosphatidylethanolamine $N$-methyltransferase pathway [33]. In our work, we found that PC and $\mathrm{PE}$, with the number of double bonds equal to 0,1 or 3 , were significantly up-regulated, while PC and $\mathrm{PE}$, with the number of double bonds equal to 2,4 or 6 , were significantly down-regulated, suggesting a strong association between PC and PE.

We found that Cer was decreased in HCC tissue. Cer is a well-known second messenger for apoptosis, senescence or autophagy [34]. Cer can be generated via hydrolysis of cell membrane SM by sphingomyelinases. We also found that SM was increased in HCC tissue. Taken together, the reduction of 
Cer in HCC tissue may decrease the cancer cell apoptosis, and the sphingomyelinase enzyme may be related to HCC.

\section{Materials and Methods}

\subsection{Materials}

HPLC-grade methanol $(\mathrm{MeOH})$, acetonitrile $\left(\mathrm{CH}_{3} \mathrm{CN}\right)$, isopropanol (IPA), formic acid as well as ammonium formate were purchased from Sigma or Fisher Scientific (Pittsburgh, PA, USA). $\mathrm{AgNO}_{3}$ and polyvinyl pyrrolidone were purchased from Sigma-Aldrich (St. Louis, MO, USA). Ultrapure water was from Milli-Q purification system (Millipore Corporation, Burlington, MA, USA). Standard lipids, including L- $\alpha$-phosphatidic acid (PA, Egg, Chicken), 1-palmitoyl-2-oleoyl-sn-glycero-3-phosphocholine (16:0/18:1 PC), 1-palmitoyl-2-arachidonoyl-sn-glycero-3-phosphocholine (16:0/20:4 PC), L- $\alpha$ phosphatidylethanolamine (PE, egg, Chicken), L- $\alpha$-phosphatidylglycerol (PG, egg, Chicken), L- $\alpha-$ phosphatidylinositol (PI, soy), L- $\alpha$-phosphatidylserine (PS, brain, Porcine), $N$-heptadecanoyl-D-erythrosphingosine (17:0 Cer), $N$-palmitoyl-D-erythro-sphingosine (16:0 Cer), $N$-palmitoyl-D-erythrosphingosylphosphorylcholine (16:0 SM), N-oleoyl-D-erythro-sphingosylphosphorylcholine (18:1 SM), $\mathrm{N}$-(octadecanoyl)-sphing-4-enine-1-phosphocholine (18:0 SM, brain) and 1,3(d5)-diheptadecanoyl2-heptadecenoyl-glycerol (d5-(17:0-17:1-17:0) TAG) were purchased from Avanti Polar Lipids (Birmingham, AL, USA). The sphingoid base of Cer and SM were all d18:1. These lipids were used for assistance of qualitative analysis and as quality control of analysis. All of the above materials were used as received without further purification. The AgNPs were synthesized using polyvinyl pyrrolidone (PVP, MW = 55,000) as ligands based on the method of Xia [35].

\subsection{Tissue Samples}

The HCC and para-carcinoma tissues were obtained from 20 patients ( $54.8 \pm 12.0$ years old) undergoing cancer resection at Peking University People's Hospital. Ethical approval of the present study was obtained from the ethical committee of Peking University People's Hospital (Beijing, China). The methods were carried out in accordance with the approved guidelines. Tissue samples were collected in tubes, quickly frozen using liquid nitrogen and stored at $-80{ }^{\circ} \mathrm{C}$ until use. All the patients were informed and the consents were obtained.

The demographics and clinical measurements of patients were displayed in Table 2. They are comprised of 15 males ( $55.9 \pm 10.8$ years old) and 5 females ( $51.2 \pm 16.0$ years old). Among them, 16 had HBV-related HCC, 1 had HCV-related HCC, 1 had HBV and HCV-related HCC, and 2 had HCC without HBV and HCV infection. The TNM stage was classified according to UICC/AJCC, 2010. The median alpha fetal protein (AFP) concentration was 421.9 (range: 2.5-1210.0, mean \pm SD: $421.9 \pm 545.5) \mathrm{ng} / \mathrm{mL}$, and $11 \mathrm{HCC}$ patients had AFP values above a threshold of $20 \mathrm{ng} / \mathrm{mL}$. In addition, there were 9 patients with vessel invasion.

Table 2. Demographics and clinical measurements of patients.

\begin{tabular}{|c|c|c|c|}
\hline \multicolumn{2}{|c|}{ Factor } & \multirow{3}{*}{$\begin{array}{c}\text { No. } \\
15 \\
5\end{array}$} & \multirow{3}{*}{$\begin{array}{c}\% \\
75 \\
25\end{array}$} \\
\hline & Male & & \\
\hline Sex & Female & & \\
\hline \multirow{2}{*}{ TNM stage } & I, II & 13 & 65 \\
\hline & III, IV & 7 & 35 \\
\hline \multirow{2}{*}{ AFP level } & $<20 \mathrm{ng} / \mathrm{mL}$ & 9 & 45 \\
\hline & $>20 \mathrm{ng} / \mathrm{mL}$ & 11 & 55 \\
\hline \multirow{2}{*}{ vessel invasion } & Yes & 9 & 45 \\
\hline & No & 11 & 55 \\
\hline
\end{tabular}




\subsection{Lipids Extraction}

Tissue samples were homogenized using Tissuelyser-24 (Shanghai Jingxing Experimental Technology, Shanghai, China). The methanol method that we have developed was used to extract lipids [36]. In brief, $50 \mu \mathrm{L}$ of homogenate (water solution containing protease inhibitor, $10.0 \mathrm{mg}$ of the tissue) from each sample was added to $950 \mu \mathrm{L}$ of $\mathrm{MeOH}$ for lipids extraction. After vortexing and centrifugation $(10,000 \times g, 5 \mathrm{~min}$, room temperature), $300 \mu \mathrm{L}$ of the supernatant was used for analysis by UPLC-ESI-QTOF mass spectrometer. $2 \mu \mathrm{L}$ of the supernatant or $2 \mu \mathrm{L}$ of $10 \times$ dilution were loaded into mass spectrometer for negative-ion or positive-ion lipids analysis, respectively.

\subsection{Tissue Sectioning}

The frozen HCC and para-carcinoma tissue were sectioned at $10 \mu \mathrm{m}$ thickness using a Leica CM1950 cryostat (Leica Microsystems $\mathrm{GmbH}$, Wetzlar, Germany) at $-18{ }^{\circ} \mathrm{C}$ and mounted onto one indium tin oxide (ITO) coated glass slides ((Type I) $1.1 \mathrm{~mm} / 100$ ea, HST Inc., Newark, NJ, USA). The glass slide was then drying for approximately $1 \mathrm{hr}$ using a vacuum desiccator. The AgNPs MALDI matrix $(2 \mathrm{mg} / \mathrm{mL})$ was sprayed on the liver tissues by a homemade electrospray-based matrix deposition device described in the previous work [17]. The slide was dried by the vacuum desiccator for approximately $1 \mathrm{hr}$ again and then was used for MALDI MSI analysis.

\subsection{UPLC-ESI-QTOF Mass Spectrometer}

Lipids profile analysis was performed using Xevo G2 QTOF mass spectrometer (Waters). Both the nebulizer and desolvation gases were nitrogen. Typical operating parameters were set as follows: the capillary voltage was $3.0 \mathrm{kV}$ or $-3.0 \mathrm{kV}$ in positive or negative ion mode, respectively; the sampling cone voltage was $40 \mathrm{~V}$, desolvation gas temperature was $500{ }^{\circ} \mathrm{C}$, the source temperature was set at $150{ }^{\circ} \mathrm{C}$, nebulization gas flow was $40 \mathrm{~L} / \mathrm{h}$, and desolvation gas flow was $400 \mathrm{~L} / \mathrm{h}$. Data were collected between $m / z 50$ and 1200. Multiplexed data acquisition (MSE), a kind of data independent acquisition mode, was performed for simultaneously acquiring MS and MS/MS data with high resolution and high accuracy. The lock spray was used to ensure reproducibility and accuracy. Leucine enkephalin $(200 \mathrm{pg} / \mathrm{mL})$ was used as lock mass in ESI $(-)(m / z$ 554.2620) and ESI $(+)(m / z$ 556.2766). The lock spray frequency was set to $5 \mathrm{~s}$, and the lock mass data were averaged over a total of 10 scans.

Samples were loaded through a LC system (I-class Acquity ultra performance liquid chromatography, Waters, Milford, MA, USA) with an auto sampler. The mobile phase A was IPA $/ \mathrm{CH}_{3} \mathrm{CN} /$ formic acid (90:10:0.1, $\left.v / v / v\right)$ containing $10 \mathrm{mM}$ ammonium formate; the mobile phase $\mathrm{B}$ was $\mathrm{CH}_{3} \mathrm{CN} /$ water/formic acid (70:30:0.1, $\left.v / v / v\right)$ containing $10 \mathrm{mM}$ ammonium formate. A HSS T3 column $(1.8 \mu \mathrm{m}, 2.1 \mathrm{~mm}$ ID $\times 100 \mathrm{~mm}$, Waters $)$ was used for the separation of lipids. The column was maintained at $55{ }^{\circ} \mathrm{C}$. The UPLC separations were $12 \mathrm{~min} /$ sample using the following scheme: (1) $0 \mathrm{~min}, 60 \% \mathrm{~B}$; (2) $10 \mathrm{~min}, 1 \% \mathrm{~B}$; (3) $12 \mathrm{~min}, 60 \% \mathrm{~B}$. All the changes were linear, and the flow rate was set at $400 \mu \mathrm{L} / \mathrm{min}$.

\subsection{MALDI-FTICR Mass Spectrometry Imaging}

MALDI-FTICR mass spectrometry imaging was performed with a Bruker SolariX mass spectrometer equipped with a $9.4 \mathrm{~T}$ superconducting magnet (Solari ${ }^{\circledR}$; Bruker, Bremen, Germany) using AgNPs as matrix. The concentration of AgNPs is $2 \mathrm{mg} / \mathrm{mL}$ dissolved in $\mathrm{CH}_{3} \mathrm{CN}_{\mathrm{H}} \mathrm{H}_{2} \mathrm{O}$ (50:50, $v / v$ ). Positive ion mode was applied in all the experiments. Mass calibrations were performed externally using sodium trifluoroacetate (NaTFA, Sofia, Bulgaria). For MALDI-FTICR MS imaging, the parameters of MS instrument was the same with the previous work [17].

\subsection{Data Processing}

Data obtained by QTOF MS were processed by Markerlynx XS (Waters). As described in detail previously [16], orthogonal partial least square-discriminant analysis (OPLS-DA) was 
used for discrimination of HCC (HCC group) and para-carcinoma tissues (Para-carcinoma group). Discriminating variables, that is, aberrant lipids, were selected according to variable importance in projection values $(\mathrm{VIP})>4$.0. The aberrant lipids were identified by searching local database established by Waters or free online databases, including Lipidmaps (http:/ / www.lipidmaps.org/) and the human metabolome database (HMDB) (http:/ / www.hmdb.ca), to precisely match the accurate molecular ion obtained by MS (mass error $<5 \mathrm{ppm}$ ). In addition, standard lipids were also used for assistance of identification of the aberrant lipids. Moreover, the fragment ions in MS/MS data obtained by collision induced dissociation (CID) were further utilized for confirmation of the structure of the aberrant lipids.

MALDI-FTICR MS Data were processed using DataAnalysis 4.0 (Bruker Daltonics, Billerica, MA, USA), FlexImaging 3.0 sofware (Bruker Daltonics, Billerica, MA, USA) and Isotope Parttern (Bruker Daltonics, Billerica, MA, USA). The lipids were identified by searching from HMDB as described before.

\section{Conclusions}

In conclusion, we have undertaken a liver lipidomics study of HCC, in which HCC and para-carcinoma tissue were used. Interestingly, it was found that TAGs with the number of double bonds more than 2 (except 56:5 and 56:4 TAG) were significantly down-regulated, and similar results were confirmed with MALDI MSI analyses; however, TAGs with the number of double bonds equal to or less than 2 (except 52:2 TG) were greatly up-regulated in HCC tissues. PC, PE and PI, with the number of double bonds equal to 0,1 or 3 , were significantly up-regulated, while PC, PE and PI (except 18:2/18:2 PI), with the number of double bonds equal to 2, 4 or 6 , were significantly down-regulated. MALDI MSI imaging of 34:1 PC also showed high expression in the tumor section. SM was up-regulated and Cer and PG were down-regulated in HCC tissues. All these molecular changes in the liver of HCC patients provide new insights into the pathobiology of the disease. Further studies, such as induction of lipid dysfunction in normal liver tissue, lipid function, and the effect of lipid on the diagnostic and prognosis, are definitely needed.

Supplementary Materials: Supplementary materials can be found at www.mdpi.com/1422-0067/18/12/2550/s1.

Acknowledgments: This work was supported by National Natural Science Foundation of China (Grant Nos. 21575146, 21321003 and 81502509) and Beijing Key Laboratory Special Fund (Grant No. Z141107004414042). We also appreciated the help of Xiaojie Tan and Xu Bai from Waters Co. (Beijing, China) for the assistance of instrument operation.

Author Contributions: Conceived and designed the experiments: Zhenwen Zhao, Jiye Zhu Prepared samples: Zhao Li, Xiao Cui. Performed the experiments: Ming Guan, Yu Lin, Yangyang Zhang. Analyzed the data: Ming Guan, Yu Lin, Yangyang Zhang, Zhenwen Zhao. Wrote the paper: Zhenwen Zhao, Ming Guan, Zhao Li, Yu Lin, Xiao Cui, Yangyang Zhang, Jiye Zhu.

Conflicts of Interest: The authors declare no conflict of interest.

\section{Abbreviations}

HCC

UPLC-ESI-QTOF MS

MALDI-FTICR MS

TAG

DB

PC

PE

PI

SM

Cer

$\mathrm{HCV}$
Hepatocellular carcinoma

Ultra high performance liquid chromatography-electronic spray ionization-QTOF mass spectrometer

Matrix assisted laser desorption ionization-fourier transform ion cyclotron resonance mass spectrometer

Triacylglycerol

Double bond

Phosphatidylcholine

Phosphoethanolamine

Phosphatidylinositol

Sphingomyelin

Ceramide

Hepatitis C virus 


\begin{tabular}{|c|c|}
\hline $\mathrm{HBV}$ & Hepatitis B virus \\
\hline NAFLD & Non-alcoholic fatty liver disease \\
\hline NASH & Non-alcoholic steatohepatitis \\
\hline LPC & Lysophosphatidylcholine \\
\hline OPLS-DA & Orthogonal partial least squared discriminant analysis \\
\hline MALDI MSI & Matrix assisted laser desorption ionization mass spectrometry imaging \\
\hline TIC & Total ion chromatogram \\
\hline TNM & Tumor node metastasis \\
\hline C-H TNM & High TNM grade (III, IV) cancer tissue \\
\hline C-L TNM & Low TNM grade (I, II) cancer tissue \\
\hline VIP & Variable importance in projection value \\
\hline RT & Retention time \\
\hline HMDB & Human Metabolome Database \\
\hline FC & Fold change \\
\hline PG & Phosphatidylglycerol \\
\hline AgNPs & Silver nanoparticles \\
\hline H\&E & Hematoxylin-eosin staining \\
\hline ESI-MS & Electrospray ionization mass spectrometry \\
\hline UPLC & Ultra high performance liquid chromatography \\
\hline PS & Phosphatidylserine \\
\hline CRC & Colorectal cancer \\
\hline SFA & Saturated fatty acid \\
\hline MUFA & Monounsaturated fatty acid \\
\hline PUFA & Polyunsaturated fatty acid \\
\hline DAG & Diacylglycerol \\
\hline $\mathrm{MeOH}$ & Methanol \\
\hline $\mathrm{CH}_{3} \mathrm{CN}$ & Acetonitrile \\
\hline IPA & Isopropanol \\
\hline PA & Phosphatidic acid \\
\hline PVP & Polyvinyl pyrrolidone \\
\hline AFP & Alpha fetal protein \\
\hline ITO & Indium tin oxide \\
\hline MSE & Multiplexed data acquisition \\
\hline NaTFA & Sodium trifluoroacetate \\
\hline CID & Collision induced dissociation \\
\hline
\end{tabular}

\section{References}

1. Siegel, R.; Ma, J.M.; Zou, Z.H.; Jemal, A. Cancer Statistics, 2014. CA Cancer J. Clin. 2014, 64, 9-29. [CrossRef] [PubMed]

2. Arzumanyan, A.; Reis, H.; Feitelson, M.A. Pathogenic mechanisms in HBV- and HCV-associated hepatocellular carcinoma. Nat. Rev. Cancer 2013, 13, 123-135. [CrossRef] [PubMed]

3. Cauchy, F.; Fuks, D.; Belghiti, J. HCC: Current surgical treatment concepts. Langenbeck Arch. Surg. 2012, 397, 681-695. [CrossRef] [PubMed]

4. Moustafa, T.; Fickert, P.; Magnes, C.; Guelly, C.; Thueringer, A.; Frank, S.; Kratky, D.; Sattler, W.; Reicher, H.; Sinner, F.; et al. Alterations in Lipid Metabolism Mediate Inflammation, Fibrosis, and Proliferation in a Mouse Model of Chronic Cholestatic Liver Injury. Gastroenterology 2012, 142, 140-151. [CrossRef] [PubMed]

5. Puri, P.; Baillie, R.A.; Wiest, M.M.; Mirshahi, F.; Choudhury, J.; Cheung, O.; Sargeant, C.; Contos, M.J.; Sanyal, A.J. A lipidomic analysis of nonalcoholic fatty liver disease. Hepatology 2007, 46, 1081-1090. [CrossRef] [PubMed]

6. Puri, P.; Wiest, M.M.; Cheung, O.; Mirshahi, F.; Sargeant, C.; Min, H.K.; Contos, M.J.; Sterling, R.K.; Fuchs, M.; Zhou, H.P.; et al. The Plasma Lipidomic Signature of Nonalcoholic Steatohepatitis. Hepatology 2009, 50, 1827-1838. [CrossRef] [PubMed] 
7. Abdelmalek, M.F.; Day, C. Sugar sweetened beverages and fatty liver disease: Rising concern and call to action. J. Hepatol. 2015, 63, 306-308. [CrossRef] [PubMed]

8. Alwahsh, S.M.; Gebhardt, R. Dietary fructose as a risk factor for non-alcoholic fatty liver disease (NAFLD). Arch. Toxicol. 2017, 91, 1545-1563. [CrossRef] [PubMed]

9. Park, E.S.; Lee, J.H.; Hong, J.H.; Park, Y.K.; Lee, J.W.; Lee, W.J.; Lee, J.W.; Kim, K.P.; Kim, K.H. Phosphatidylcholine Alteration Identified Using MALDI Imaging MS in HBV-Infected Mouse Livers and Virus-Mediated Regeneration Defects. PLoS ONE 2014, 9, e103955. [CrossRef] [PubMed]

10. Kessler, S.M.; Simon, Y.; Gemperlein, K.; Gianmoena, K.; Cadenas, C.; Zimmer, V.; Pokorny, J.; Barghash, A.; Helms, V.; van Rooijen, N.; et al. Fatty Acid Elongation in Non-Alcoholic Steatohepatitis and Hepatocellular Carcinoma. Int. J. Mol. Sci. 2014, 15, 5762-5773. [CrossRef] [PubMed]

11. Matsuzaka, T.; Atsumi, A.; Matsumori, R.; Nie, T.; Shinozaki, H.; Suzuki-Kemuriyama, N.; Kuba, M.; Nakagawa, Y.; Ishii, K.; Shimada, M.; et al. Elovl6 Promotes Nonalcoholic Steatohepatitis. Hepatology 2012, 56, 2199-2208. [CrossRef] [PubMed]

12. Muir, K.; Hazim, A.; He, Y.; Peyressatre, M.; Kim, D.Y.; Song, X.L.; Beretta, L. Proteomic and Lipidomic Signatures of Lipid Metabolism in NASH-Associated Hepatocellular Carcinoma. Cancer Res. 2013, 73, 4722-4731. [CrossRef] [PubMed]

13. Patterson, A.D.; Maurhofer, O.; Beyoglu, D.; Lanz, C.; Krausz, K.W.; Pabst, T.; Gonzalez, F.J.; Dufour, J.F.; Idle, J.R. Aberrant Lipid Metabolism in Hepatocellular Carcinoma Revealed by Plasma Metabolomics and Lipid Profiling. Cancer Res. 2011, 71, 6590-6600. [CrossRef] [PubMed]

14. Lin, L.; Ding, Y.; Wang, Y.; Wang, Z.; Yin, X.; Yan, G.; Zhang, L.; Yang, P.; Shen, H. Functional lipidomics: Palmitic acid impairs hepatocellular carcinoma development by modulating membrane fluidity and glucose metabolism. Hepatology 2017, 66, 432-448. [CrossRef] [PubMed]

15. Wenk, M.R. Lipidomics: New Tools and Applications. Cell 2010, 143, 888-895. [CrossRef] [PubMed]

16. Zhang, Y.; Liu, Y.; Li, L.; Wei, J.; Xiong, S.; Zhao, Z. High resolution mass spectrometry coupled with multivariate data analysis revealing plasma lipidomic alteration in ovarian cancer in Asian women. Talanta 2016, 150, 88-96. [CrossRef] [PubMed]

17. Li, S.; Zhang, Y.; Liu, J.; Han, J.; Guan, M.; Yang, H.; Lin, Y.; Xiong, S.; Zhao, Z. Electrospray deposition device used to precisely control the matrix crystal to improve the performance of MALDI MSI. Sci. Rep. 2016, 6. [CrossRef] [PubMed]

18. Li, L.; Wang, L.L.; Shangguan, D.H.; Wei, Y.B.; Han, J.J.; Xiong, S.X.; Zhao, Z.W. Ultra-high-performance liquid chromatography electrospray ionization tandem mass spectrometry for accurate analysis of glycerophospholipids and sphingolipids in drug resistance tumor cells. J. Chromatogr. A 2015, 1381, 140-148. [CrossRef] [PubMed]

19. Huang, C.F.; Freter, C. Lipid Metabolism, Apoptosis and Cancer Therapy. Int. J. Mol. Sci. 2015, 16, 924-949. [CrossRef] [PubMed]

20. Hummel, J.; Segu, S.; Li, Y.; Irgang, S.; Jueppner, J.; Giavalisco, P. Ultra performance liquid chromatography and high resolution mass spectrometry for the analysis of plant lipids. Front. Plant Sci. 2011, 2, 17. [CrossRef] [PubMed]

21. Zhao, Z.W.; Xiao, Y.J.; Elson, P.; Tan, H.Y.; Plummer, S.J.; Berk, M.; Aung, P.P.; Lavery, I.C.; Achkar, J.P.; Li, L.; et al. Plasma lysophosphatidylcholine levels: Potential biomarkers for colorectal cancer. J. Clin. Oncol. 2007, 25, 2696-2701. [CrossRef] [PubMed]

22. Li, S.; Guo, B.; Song, J.W.; Deng, X.L.; Cong, Y.S.; Li, P.F.; Zhao, K.; Liu, L.H.; Xiao, G.; Xu, F.; et al. Plasma choline-containing phospholipids: Potential biomarkers for colorectal cancer progression. Metabolomics 2013, 9, 202-212. [CrossRef]

23. Van Thiel, D.H.; Alwahsh, S.M.; Ramadori, G. Metabolic Disease and Hepatocellular Carcinoma. In Hepatocellular Carcinoma, Diagnosis and Treatment, 3rd ed.; Brian, I.C., Ed.; Springer: Basel, Switzerland, 2016; pp. 287-301.

24. Aguilera-Mendez, A.; Alvarez-Delgado, C.; Hernandez-Godinez, D.; Fernandez-Mejia, C. Hepatic Diseases Related to Triglyceride Metabolism. Mini Rev. Med. Chem. 2013, 13, 1691-1699. [CrossRef] [PubMed]

25. Miller, M.; Stone, N.J.; Ballantyne, C.; Bittner, V.; Criqui, M.H.; Ginsberg, H.N.; Goldberg, A.C.; Howard, W.J.; Jacobson, M.S.; Kris-Etherton, P.M.; et al. Triglycerides and Cardiovascular Disease A Scientific Statement From the American Heart Association. Circulation 2011, 123, 2292-2333. [CrossRef] [PubMed] 
26. Chapman, M.J.; Ginsberg, H.N.; Amarenco, P.; Andreotti, F.; Boren, J.; Catapano, A.L.; Descamps, O.S.; Fisher, E.; Kovanen, P.T.; Kuivenhoven, J.A.; et al. Triglyceride-rich lipoproteins and high-density lipoprotein cholesterol in patients at high risk of cardiovascular disease: Evidence and guidance for management. Eur. Heart J. 2011, 32, 1345-1361. [CrossRef] [PubMed]

27. Di Angelantonio, E.; Sarwar, N.; Perry, P.; Kaptoge, S.; Ray, K.K.; Thompson, A.; Wood, A.M.; Lewington, S.; Sattar, N.; Packard, C.J.; et al. Major Lipids, Apolipoproteins, and Risk of Vascular Disease. J. Am. Med. Assoc. 2009, 302, 1993-2000.

28. Alberti, K.; Eckel, R.H.; Grundy, S.M.; Zimmet, P.Z.; Cleeman, J.I.; Donato, K.A.; Fruchart, J.C.; James, W.P.T.; Loria, C.M.; Smith, S.C.; et al. Harmonizing the Metabolic Syndrome: A Joint Interim Statement of the International Diabetes Federation Task Force on Epidemiology and Prevention; National Heart, Lung, and Blood Institute; American Heart Association; World Heart Federation; International Atherosclerosis Society; and International Association for the Study of Obesity. Circulation 2009, 120, 1640-1645. [PubMed]

29. Calder, P.C. n-3 polyunsaturated fatty acids and inflammation: From molecular biology to the clinic. Lipids 2003, 38, 343-352. [CrossRef] [PubMed]

30. Mori, T.A.; Woodman, R.J.; Burke, V.; Puddey, I.B.; Croft, K.D.; Beilin, L.J. Effect of eicosapentaenoic acid and docosahexaenoic acid on oxidative stress and inflammatory markers in treated-hypertensive type 2 diabetic subjects. Free Radic. Biol. Med. 2003, 35, 772-781. [CrossRef]

31. Chapkin, R.S.; Davidson, L.A.; Ly, L.; Weeks, B.R.; Lupton, J.R.; McMurray, D.N. Immunomodulatory effects of (n-3) fatty acids: Putative link to inflammation and colon cancer. J. Nutr. 2007, 137, 200S-204S. [PubMed]

32. Yonezawa, Y.; Hada, T.; Uryu, K.; Tsuzuki, T.; Eitsuka, T.; Miyazawa, T.; Murakami-Nakai, C.; Yoshida, H.; Mizushina, Y. Inhibitory effect of conjugated eicosapentaenoic acid on mammalian DNA polymerase and topoisomerase activities and human cancer cell proliferation. Biochem. Pharmacol. 2005, 70, 453-460. [CrossRef] [PubMed]

33. Vance, D.E.; Vance, J.E. Phospholipid biosynthesis in eukaryotes. In Biochemistry of Lipids, Lipoproteins and Membranes, 5th ed.; Vance, J.E., Ed.; Elsevier: New York, NY, USA, 2008; pp. 213-244.

34. Hajj, C.; Becker-Flegler, K.A.; Haimovitz-Friedman, A. Novel mechanisms of action of classical chemotherapeutic agents on sphingolipid pathways. Biol. Chem. 2015, 396, 669-679. [CrossRef] [PubMed]

35. Yin, Y.; Li, Z.-Y.; Zhong, Z.; Gates, B.; Xia, Y.; Venkateswaran, S. Synthesis and characterization of stable aqueous dispersions of silver nanoparticles through the Tollens process Electronic supplementary information (ESI) available: Photographs of silver mirror, and of stable dispersions of silver nanoparticles from mixing diluted silvering solutions under sonication at various times. J. Mater. Chem. 2002, 12, 522-527.

36. Zhao, Z.W.; Xu, Y. An extremely simple method for extraction of lysophospholipids and phospholipids from blood samples. J. Lipid Res. 2010, 51, 652-659. [CrossRef] [PubMed] 